\title{
Multivariate Analysis and Contamination Studies of Elemental Profile in Ife/ljesa Goldmine Tailings, Southwestern, Nigeria
}

\author{
A.O. Fatoye ${ }^{1,2,{ }^{*}}$, A.O. Adebayo ${ }^{1}$, W.B. Tomori ${ }^{1}$ \\ ${ }^{1}$ Department of Chemistry, Federal University of Technology, Akure, Ondo State, Nigeria. \\ ${ }^{2}$ Department of Science Technology, Federal Polytechnic Ado Ekiti, Ekiti State, Nigeria. \\ Abiodun.fatoye@yahoo.com
}

Keyword: Tailings, Goldmine, Concentration, Correlation, Component, Contamination.

\begin{abstract}
The concentration of metals in the tailings of Ife/Ijesa goldmine, Nigeria was identified by using Proton Induced X-Ray Emission spectrometry as the main analytical tools. A total of 75 samples of the tailings were collected. Correlation, principal component and cluster analyses suggested probable natural and anthropogenic sources of the metals in the tailings. The contamination level of heavy metals was assessed on the basis of geo-accumulation index $\left(I_{g e o}\right)$, and ecological risk. The analysis of $I_{\text {geo }}$ revealed moderately-heavily to heavily extremely contaminated. The value of $E_{r}$ showed a low level of heavy metals except $\mathrm{Cu}$ which shows considerable contamination
\end{abstract}

\section{Introduction}

Mineral resources are abundant in Nigeria and are spread across the 36 states of the federation. In recent year, its exploitation has greatly enhances Nigeria social and economic development positively.

Mining operation is one of the human/industrial activities that gives rise to soil erosion and environmental contamination by generating waste (tailings) during the extraction, beneficiation, and processing of minerals. Scattered tailings on mining site also contaminate the environment (air, water, soil, and wetland sediments) by dissemination of particles carrying metals by wind action and/or by runoff from the tailings after closure [1].

Mining and smelting are two significant aspects of operations that cause heavy metal contamination in the environment due to the activities such as mineral excavation, ore transportation, smelting and refining [2]. Moreover, mining activities contribute to heavy metal pollution of the environment and their progressive accumulation in soils surrounded by mines, which may result in increased heavy metal uptake by plants [3, 4].

Natural geochemical sources of heavy metals include weathering and other pedogenic processes acting on rock fragments, and are usually at relatively low concentrations while anthropogenic sources such as mining and industrial metallurgic process activities are also been reported to increase $\mathrm{As}, \mathrm{Cd}, \mathrm{Cu}, \mathrm{Ni}$, and $\mathrm{Zn}$ concentrations in the environment [5-9].

Heavy metal pollution is considered as one of the most critical contaminants in the environmental due to their persistence, toxicity, bioaccumulation and non-biodegradable properties and all these have negative consequence in plants, animals and humans via the food chain [10].

The main purposes of the present study were to: (a) determine total concentrations of elements in mine tailings from different gold mining villages in Ife/Ijesa zone (b) identify their natural or anthropogenic origin by using correlation analysis, principal component analysis (PCA) and cluster analysis (CA), and (c) assess the levels of contamination based on the geo-accumulation index $\left(I_{\text {geo }}\right)$, and ecological risk $\left(E_{r}\right)$. The results can provide a baseline for use in future environmental impact assessments and to guide pollution mitigation targets in the zone. 


\section{Materials and Methods}

\section{Study area}

This study was carried out in 15 townships in Ife/Ijesa zone, located in the southwestern Nigerian as shown in Fig. 1. Dominant land-use is agriculture, especially cultivation of cash (mainly cocoa, kola, oil palm and plantain) and food crops (including cassava, yam, and fruits).

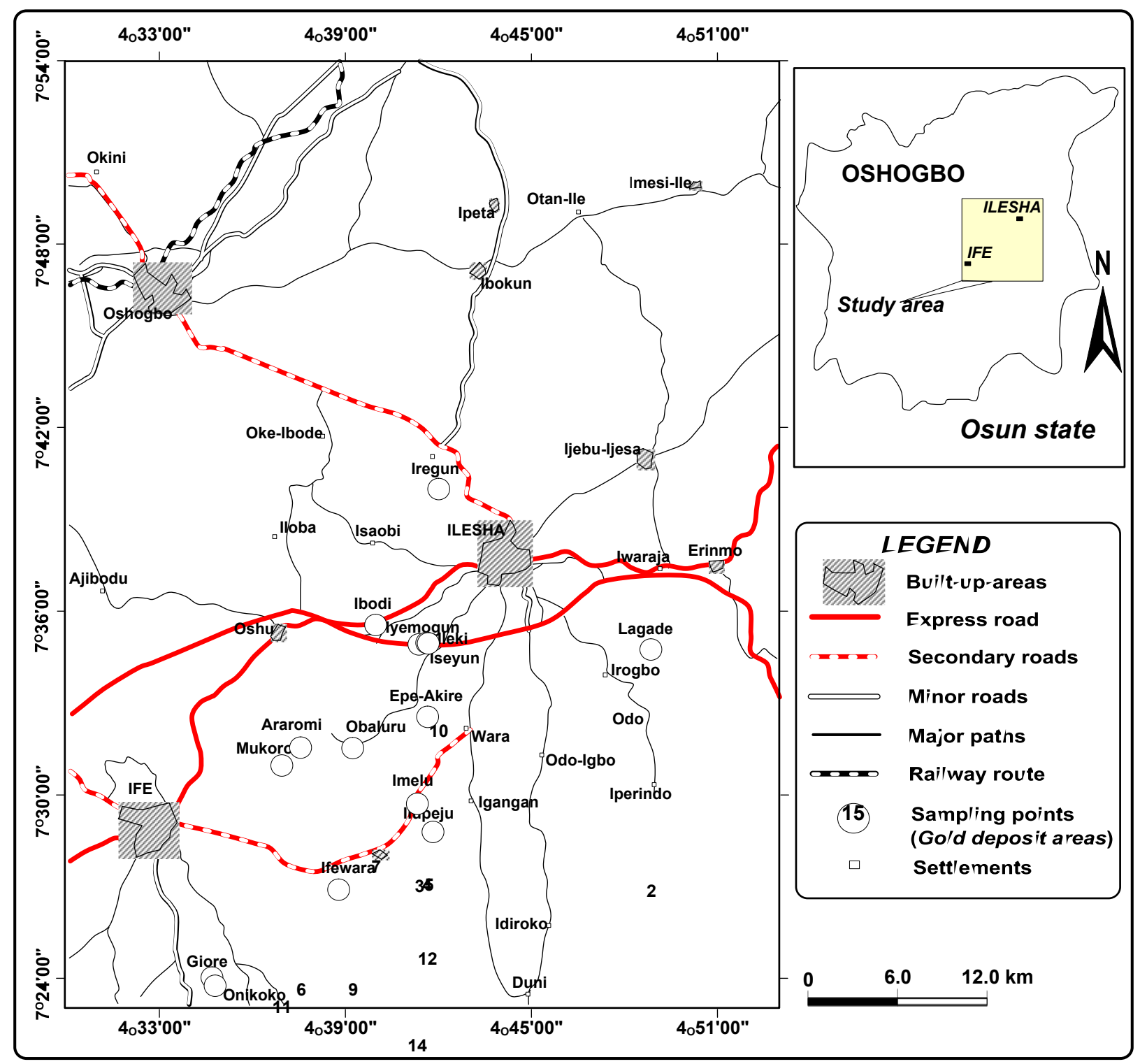

Figure 1. Location map showing the access road to the sampling point and study area (Gold deposit zones) at Ife-Ijesa.

\section{Tailings sampling}

A total of 75 tailing samples were collected from different locations which spread across the mining area in Ife/Ilesa geographical zone. The coordinate of each sampling point were taken using GPS. The samples were kept in air tight polyethylene bags. In the laboratory, all the samples were air-dried, ground and passed through a $0.8 \mathrm{~mm}$ sieve.

\section{Sample Preparation}

The tailings sample were pulverized/crushed to size less than $125 \mathrm{~nm}$.Then, drop of toluene acid (binder) was then added to $0.5 \mathrm{~g}$ of the powdered sample and crushing continued until the mixture was returned to fine powder again. The $0.5 \mathrm{~g}$ weighed of the crushed sample was compressed under a hydraulic press machine at 10-tone pressure and converted from fine powder to 
pellet form. The pellet were carefully labeled, covered with mila and stored in partitioned sample storage plastic container for analysis.

The pelletized soil sample was then analyzed using particle induced x-ray Emission (PIXE) techniques. The PIXE provides a rapids and non-destructive method for the analysis of trace and major element in geological, environmental and biological sample.

\section{Chemical analysis}

The samples were analyzed using Proton Induce X-Ray Emission (PIXE) with $30 \mathrm{MeV}$ proton beam obtained from Centre for Energy Research and Development (CERD) ion beam analysis (IBA) facility, with a beam spot of $4 \mathrm{~mm}$ in diameter and a low beam current of 3-6nA . The irradiation was for about 10-20 minutes. A Canberra Si (Li) detector model ESTX 30-150, beryllium thickness of $25 \mathrm{~mm}$, with full width half maximum (FWHM) OF $150 \mathrm{eV}$ at $5.9 \mathrm{KeV}$, with the associated pulse processing electronics, and a Canberra Genie 2000 (3.1) MCA card interfaced to a PC were used for the x-ray data acquisition with respect to the beam director, the sample's normal was located at $\mathrm{OO}$ and the $\mathrm{Si}(\mathrm{Li})$ detector at $45^{\circ}$. The PIXE set-up was calibrated using some pure element standards and NIST geological standard NBS278.

\section{Statistical analysis}

To determine the trend of analytical data, correlation analysis, PCA and CA were used. PCA and CA are the most common multivariate statistical methods used in environmental studies [11, 12].

PCA, is commonly adopted to extract a smaller number of independent factors (principal components) among available data for analyzing variables relationships [11, 13]. PCA can minimize the number of correlated variables to a smaller set of orthogonal factors, making it easier to interpret a given multidimensional system by displaying the correlations among the original variables. Principal components are those whose eigenvalues exceed 1 [14].

The CA technique consist an unsupervised classification procedure that involves measuring either the distance or the similarity between objects to be clustered. Objects are grouped in clusters in terms of their similarity. The initial assumption is that the nearness of objects in the space defined by the variables reflects the similarity of their properties [15].

In the current research, statistical analyses such as correlation coefficient, PCA and CA were used for investigating pollutants sources and elucidate the latent relationships between variables/ samples using SPSS package version 16.0 for Windows.

\section{Pollution Level Assessment Methods}

\section{Geo accumulation index $\left(I_{g e o}\right)$}

The contamination levels of heavy metals in soils were assessed by geo accumulation index $\left(I_{\text {geo }}\right)$.

$$
I_{\text {geo }}=\log _{2}\left[C_{n} /\left(1.5 B_{n}\right)\right]
$$

where $\mathrm{C}_{\mathrm{n}}$ is the measured concentration of heavy metal $\mathrm{n}$ in the soils, $B_{n}$ the geochemical background concentration of metal $\mathrm{n}$, and 1.5 is the background matrix correction factor due to lithogenic effects; $I_{\text {geo }} \leq 0$, indicate practically uncontaminated; $I_{\text {geo }} \leq 1$, indicate uncontaminatedmoderate; $I_{\text {geo }} \leq 2$, indicate moderately uncontaminated; $I_{\text {geo }} \leq 3$, indicate moderately-heavily contaminated; $I_{g e o} \leq 4$, indicate heavily contaminated; $I_{g e o} \leq 5$, indicate heavily- extremely contaminated [16]. 


\section{Ecological risk}

The method of determine ecological risk of heavy metals originally introduced by [17]), and has been adopted recently in environmental studies [18]. Hence, the potential ecological risk index (PERI) was calculated to determine the degree of heavy metal pollution in the tailings of gold mining site in Ife/Ijesa zone as follows:

Assessment of soil contamination is performed by the contamination factor $\left(\mathrm{C}_{\mathrm{f}}^{\mathrm{i}}\right)$ and degree of contamination $\left(\mathrm{C}_{\mathrm{d}}\right)[17]$.

$$
C_{f}^{i}=C_{s}^{i} / C_{n}^{i}, \quad C_{d}=\sum_{i}^{m} C_{f}^{i}
$$

where $\mathrm{C}_{\mathrm{s}}{ }^{\mathrm{i}}$ is the content of metal $\mathrm{I}$, and $\mathrm{C}_{\mathrm{n}}{ }^{\mathrm{i}}$ is the reference value, baseline level, or national criteria of metal $\mathrm{i}$.

An ecological risk factor $\left(E_{r}^{i}\right)$ to quantitatively express the potential ecological risk of a given contaminant also suggested by HAKANSON is

$$
E_{r}^{i}=T_{r}^{i} C_{f}^{i}
$$

where $C_{f}{ }^{i}$ is contamination factor and $T_{r}^{i}$ is toxic-response factor of heavy metals i are:

$$
\begin{aligned}
& \mathrm{T}_{\mathrm{r}}^{\mathrm{Zn}}=1 ; \mathrm{T}_{\mathrm{r}}^{\mathrm{Pb}}=5 ; \mathrm{T}_{\mathrm{r}}^{\mathrm{Cd}}=30 ; \mathrm{T}_{\mathrm{r}}^{\mathrm{Cu}}=5 ; \mathrm{T}_{\mathrm{r}}^{\mathrm{Ni}}=5 ; \mathrm{T}_{\mathrm{r}}^{\mathrm{Cr}}=2 \text {. } \\
& I_{r}=\sum_{i}^{n} E_{r}^{i}=\sum_{i}^{n} T_{r}^{i} C_{f}^{i}=\sum_{i}^{n} T_{r}^{i} C_{s}^{i} / C_{n}^{i}
\end{aligned}
$$

The following classes are used to describe risk levels: $C_{f} \leq 1$, low contamination; $C_{f} \leq 3$, moderate contamination; $C_{f} \leq 6$, considerably contaminated; $C_{f} \geq 6$, very high contaminated. $C_{d} \leq 8$, low degree of contamination; $C_{d} \leq 16$, moderate degree of contamination; $C_{d} \leq 32$, considerable degree of contamination; $C_{d} \geq 32$, very high degree of contamination. $E_{r} \leq 40$, low potential ecological risk; $E_{r} \leq 80$, moderate potential ecological risk; $E_{r} \leq 160$, considerable potential ecological risk; $E_{r} \leq 320$, high potential ecological risk; $E_{r} \geq 320$, very high potential ecological risk. $I_{r} \leq 150$, low ecological risk index; $I_{r} \leq 300$, moderate ecological risk index; $I_{r} \leq$ 600 , considerable ecological risk index; $I_{r} \geq 600$, very high ecological risk index.

\section{Results and Discussion}

\section{Multivariate analysis results (Principal component analysis)}

The PCA was applied to identify possible sources of pollutants in the mine tailings by applying varimax rotation with Kaiser normalization. By extracting the eigenvalues and eigenvectors from the correlation matrix, the numbers of significant factors, the percentage of variance explained by each of them were calculated by using the software package of SPSSv10.0 and the results were given in

Table 1 as expected, four factors whose eigenvalues $>1$ was selected, out of which the three prominent factors were selected for three dimensional plots of the PCA loadings presented in Fig. 2. Principal factors $>0.5$ are bolded in each column and the relationship among the fourteen element were readily observed. 
Table 1. The result principal component analysis $(n=75)$.

\begin{tabular}{|c|c|c|c|c|c|c|c|c|c|}
\hline \multirow[t]{2}{*}{ Component } & \multicolumn{3}{|c|}{ Initial Eigenvalue } & \multicolumn{3}{|c|}{ Extraction Sum of Square Loading } & \multicolumn{3}{|c|}{ Rotation Sums of Squared Loading } \\
\hline & Total & $\begin{array}{l}\% \text { of } \\
\text { Variance }\end{array}$ & $\begin{array}{c}\text { Cumulative } \\
\%\end{array}$ & Total & $\begin{array}{l}\% \text { of } \\
\text { Variance }\end{array}$ & Cumulative $\%$ & Total & $\%$ of Variance & Cumulative $\%$ \\
\hline 1 & 5.779 & 41.279 & 41.279 & 5.779 & 41.279 & 41.279 & 4.059 & 28.995 & 28.995 \\
\hline 2 & 3.257 & 23.266 & 64.545 & 3.257 & 23.266 & 64.545 & 3.725 & 26.610 & 55.605 \\
\hline 3 & 1.676 & 11.974 & 76.519 & 1.676 & 11.974 & 76.519 & 2.371 & 16.933 & 72.538 \\
\hline 4 & 1.004 & 7.170 & 83.689 & 1.004 & 7.170 & 83.689 & 1.561 & 11.151 & 83.689 \\
\hline 5 & .917 & 6.553 & 90.242 & & & & & & \\
\hline 6 & .591 & 4.224 & 94.467 & & & & & & \\
\hline 7 & .225 & 1.606 & 96.073 & & & & & & \\
\hline 8 & .183 & 1.304 & 97.377 & & & & & & \\
\hline 9 & .140 & .997 & 98.374 & & & & & & \\
\hline 10 & .112 & .798 & 99.172 & & & & & & \\
\hline 11 & .057 & .404 & 99.576 & & & & & & \\
\hline 12 & .053 & .376 & 99.953 & & & & & & \\
\hline 13 & .007 & .047 & 100.000 & & & & & & \\
\hline
\end{tabular}

Table 2. Pearson's correlation coefficients matrix among the metals concentration in the tailings.

\begin{tabular}{|c|c|c|c|c|c|c|c|c|c|c|c|c|c|c|}
\hline & $\mathrm{Na}$ & $M g$ & $A l$ & $S i$ & $P$ & $\mathrm{Cl}$ & $K$ & $\mathrm{Ca}$ & $T i$ & $\mathrm{Cr}$ & $M n$ & $\mathrm{Fe}$ & $\mathrm{Cu}$ & $Z n$ \\
\hline $\mathrm{Na}$ & 1 & & & & & & & & & & & & & \\
\hline Mg & 0.771837 & 1 & & & & & & & & & & & & \\
\hline Al & -0.32588 & -0.45025 & 1 & & & & & & & & & & & \\
\hline $\mathbf{S i}$ & -0.17953 & -0.21892 & -0.03132 & 1 & & & & & & & & & & \\
\hline $\mathbf{P}$ & 0.443778 & 0.492115 & -0.17694 & -0.07555 & 1 & & & & & & & & & \\
\hline Cl & -0.29363 & -0.15655 & -0.15495 & 0.134093 & 0.621672 & 1 & & & & & & & & \\
\hline $\mathbf{K}$ & 0.249032 & 0.086345 & -0.40848 & 0.303291 & -0.21956 & -0.25644 & 1 & & & & & & & \\
\hline $\mathrm{Ca}$ & 0.762026 & 0.902993 & -0.34452 & -0.19745 & 0.651164 & 0.084039 & -0.08416 & 1 & & & & & & \\
\hline $\mathbf{T i}$ & 0.097922 & 0.098616 & 0.040315 & -0.37019 & 0.340364 & 0.270605 & -0.64252 & 0.309743 & 1 & & & & & \\
\hline $\mathrm{Cr}$ & 0.213096 & 0.540872 & -0.09073 & -0.43269 & 0.473404 & 0.298001 & -0.53944 & 0.66529 & 0.488272 & 1 & & & & \\
\hline Mn & 0.531115 & 0.653837 & -0.18551 & -0.28245 & 0.86786 & 0.432326 & -0.36397 & 0.78756 & 0.523843 & 0.677412 & 1 & & & \\
\hline $\mathrm{Fe}$ & -0.15674 & -0.06257 & 0.548985 & -0.17695 & 0.532378 & 0.467916 & -0.70169 & 0.115756 & 0.417118 & 0.52364 & 0.502279 & 1 & & \\
\hline $\mathrm{Cu}$ & -0.07099 & 0.120011 & 0.360185 & -0.1446 & 0.269415 & 0.16913 & -0.74667 & 0.326247 & 0.465234 & 0.633502 & 0.479434 & 0.656551 & 1 & \\
\hline Zn & 0.240594 & 0.40578 & 0.055191 & -0.13754 & 0.267779 & 0.022806 & -0.60682 & 0.556967 & 0.591801 & 0.767561 & 0.507556 & 0.391583 & 0.761909 & 1 \\
\hline
\end{tabular}

Component Plot in Rotated Space

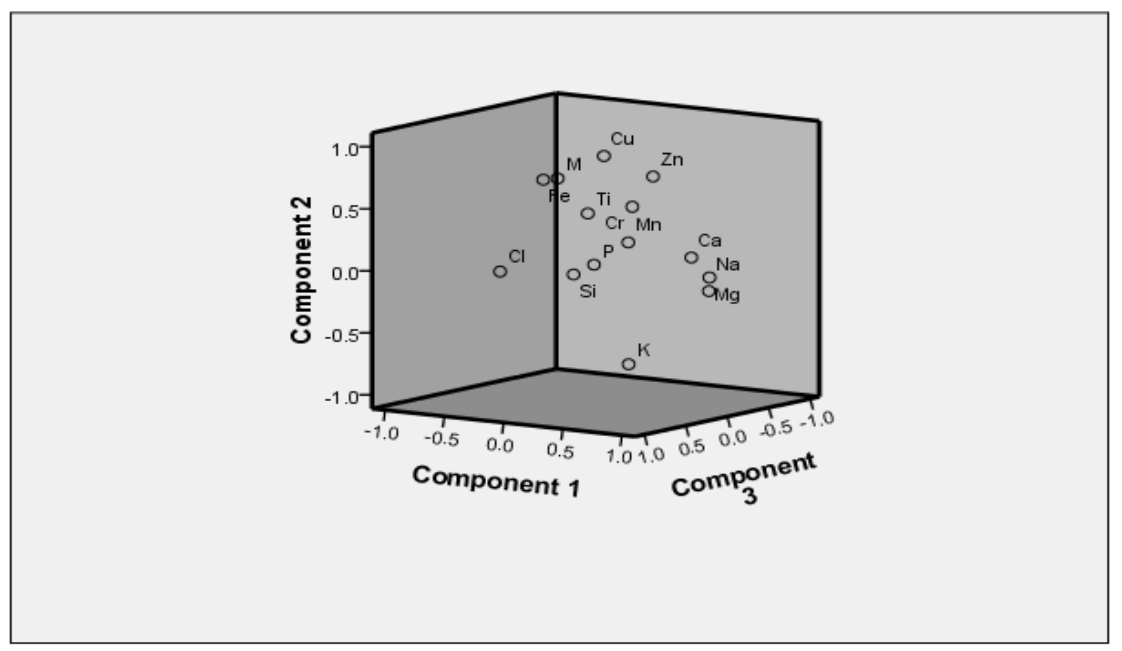

Figure 2. PCA results in the three dimensional space plot of loadings of the first three principal components. 
At Table 3, the first factor explains $29 \%$ of the total variance and load heavily on $\mathrm{Na}, \mathrm{Mg}, \mathrm{Ca}$ and $\mathrm{Mn}$ while the second factor explain $27 \%$ of total variance and loads on $\mathrm{Cr}, \mathrm{Al}, \mathrm{Fe}, \mathrm{Cu}$ and $\mathrm{Zn}$. Also, third factor explains $17 \%$ of the total variance and load on $\mathrm{Cr}, \mathrm{Cl}$ and $\mathrm{P}$. Fig. 2 shows that, heavy metals in the three dimensional PCA loading plot, are separated by a large distance which may suggest that the elements are poorly correlated and have different sources which may be natural or anthropogenic source. The main anthropogenic source in the area is mineral exploration.

Table 3. Varimax rotated loadings and communalities for the gold mine tailing samples ( $\mathrm{n}=75$, only those larger than 0.1 are shown and loading $>0.6$ are bold).

\begin{tabular}{|c|c|c|c|c|c|}
\hline \multirow[t]{2}{*}{ Element } & \multicolumn{4}{|c|}{ Rotated Component Matrix } & \multirow[t]{2}{*}{ Communalities } \\
\hline & 1 & 2 & 3 & 4 & \\
\hline $\mathrm{Na}$ & .879 & & & & .805 \\
\hline $\mathrm{Mg}$ & .954 & & & & .919 \\
\hline $\mathrm{Al}$ & & .619 & & & .664 \\
\hline $\mathrm{Si}$ & & & & & .845 \\
\hline $\mathrm{P}$ & .526 & .166 & .772 & & .900 \\
\hline $\mathrm{Cl}$ & & .070 & .958 & & .941 \\
\hline $\mathrm{K}$ & 138 & & & & .858 \\
\hline $\mathrm{Ca}$ & .936 & .180 & .182 & & .950 \\
\hline $\mathrm{Ti}$ & .129 & .467 & .279 & .581 & .650 \\
\hline $\mathrm{Cr}$ & .497 & .557 & .268 & .391 & .782 \\
\hline $\mathrm{Mn}$ & .669 & .330 & .562 & 219 & .920 \\
\hline $\mathrm{Fe}$ & & .748 & .493 & & .817 \\
\hline $\mathrm{Cu}$ & .143 & .907 & .104 & & .857 \\
\hline $\mathrm{Zn}$ & .462 & .754 & & .157 & .808 \\
\hline$\%$ Variance & 28.995 & 26.610 & 16.933 & 11.151 & 83.689 \\
\hline
\end{tabular}

\section{Cluster Analysis}

Before CA, the variables were standardized by means of Z-scores; then Euclidean distances for similarities in the variable were calculated. The CA results are shown in Fig. 3 as a dendogram. The cluster has three bigger subgroup; the first group contains only the variables $\mathrm{Na}, \mathrm{Zn}, \mathrm{Cl}, \mathrm{Cr}, \mathrm{Cu}$, $\mathrm{P}, \mathrm{Mn}, \mathrm{Mg}$ and $\mathrm{Ca}$. The second one includes $\mathrm{K}$ and Ti. The third one contains $\mathrm{Al}$ and Fe.

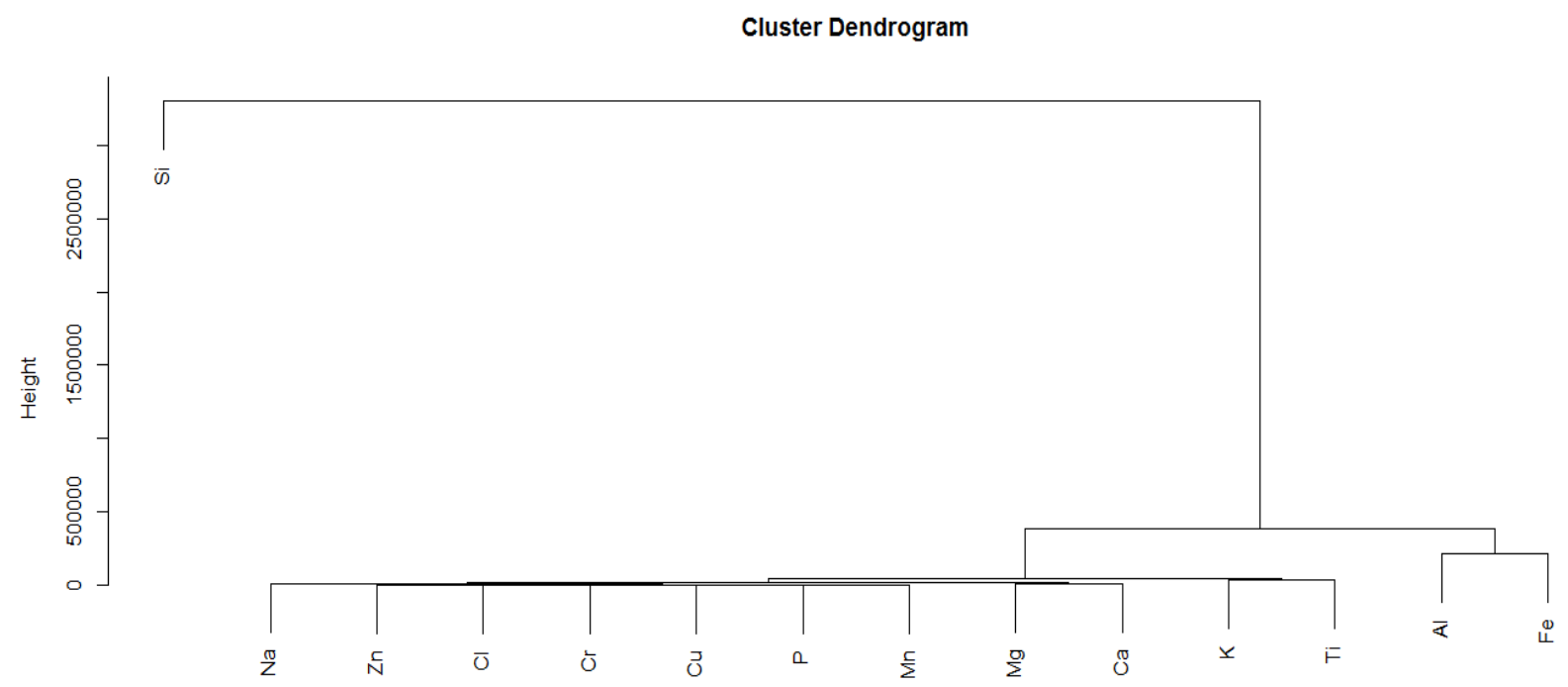

Figure 3. Dendogram results from ward's method of hierarchical cluster analysis of 13 elements and 75 samples. Similarities have been calculated from Euclidean distance. 


\section{Geo-accumulation index and Ecological risks analysis}

The $I_{g e o}$ stands for "contamination" level, and the $E_{r}$ for "pollution" level. Thus, it can be seen that the $I_{\text {geo }}$ method is best applied to accumulation levels of individual metals, while the potential ecological risk index describes the ecological risk caused by pollutants [18]. The results of geo-accumulation evaluation as shown in Table 4 indicated that $\mathrm{Cr}, \mathrm{Mn}, \mathrm{Cu}, \mathrm{Zn}, \mathrm{Pb}$, Ni had moderately-heavily to heavily extremely contaminated in the tailings, but their ecological risks were relatively low. On the other hand, these metals are not at health-threatening levels, but their environmental accumulation merits more attention. To produce more comprehensive and accurate assessment results, both assessment methods should be used when evaluating the environmental quality.

The $E_{r}$ results of six heavy metals ("except Fe, which lacked a toxic response factor") in Ife/Ijesa goldmine tailings are shown in Table 5 and Fig. $4 \mathrm{a} \& 4 \mathrm{~b}$ respectively. The average $E_{r}$ values of heavy metals showed decreasing order of: $\mathrm{Cu}>\mathrm{Cr}>\mathrm{Mn}>\mathrm{Zn}>\mathrm{Ni}>\mathrm{Pb}$. The results indicated that the concentration range of $\mathrm{Cu}$ have low and considerable potential ecological risk respectively; while $\mathrm{Cr}, \mathrm{Mn}, \mathrm{Zn}$, Ni and $\mathrm{Pb}$ have low potential risk. Based on these results, most sampling locations shows low ecologigal risk index, which means these metals, may not have adverse effect on the ecosystem.

Table 4. The Values of $I_{g e o}$ for Each Metal.

\begin{tabular}{|l|l|}
\hline Heavy Metal & $I_{\text {geo }}$ value \\
\hline $\mathrm{Cr}$ & 5.7818 \\
\hline $\mathrm{Mn}$ & 4.0349 \\
\hline $\mathrm{Cu}$ & 7.46 \\
\hline $\mathrm{Zn}$ & 3.95 \\
\hline $\mathrm{Pb}$ & 3.99 \\
\hline $\mathrm{Ni}$ & 2.76 \\
\hline
\end{tabular}

Table 5. The value of $C_{f}, C_{d}, E_{r}$ and $I_{r}$ for studied heavy metals in Ife/Ijesa goldmine tailings.

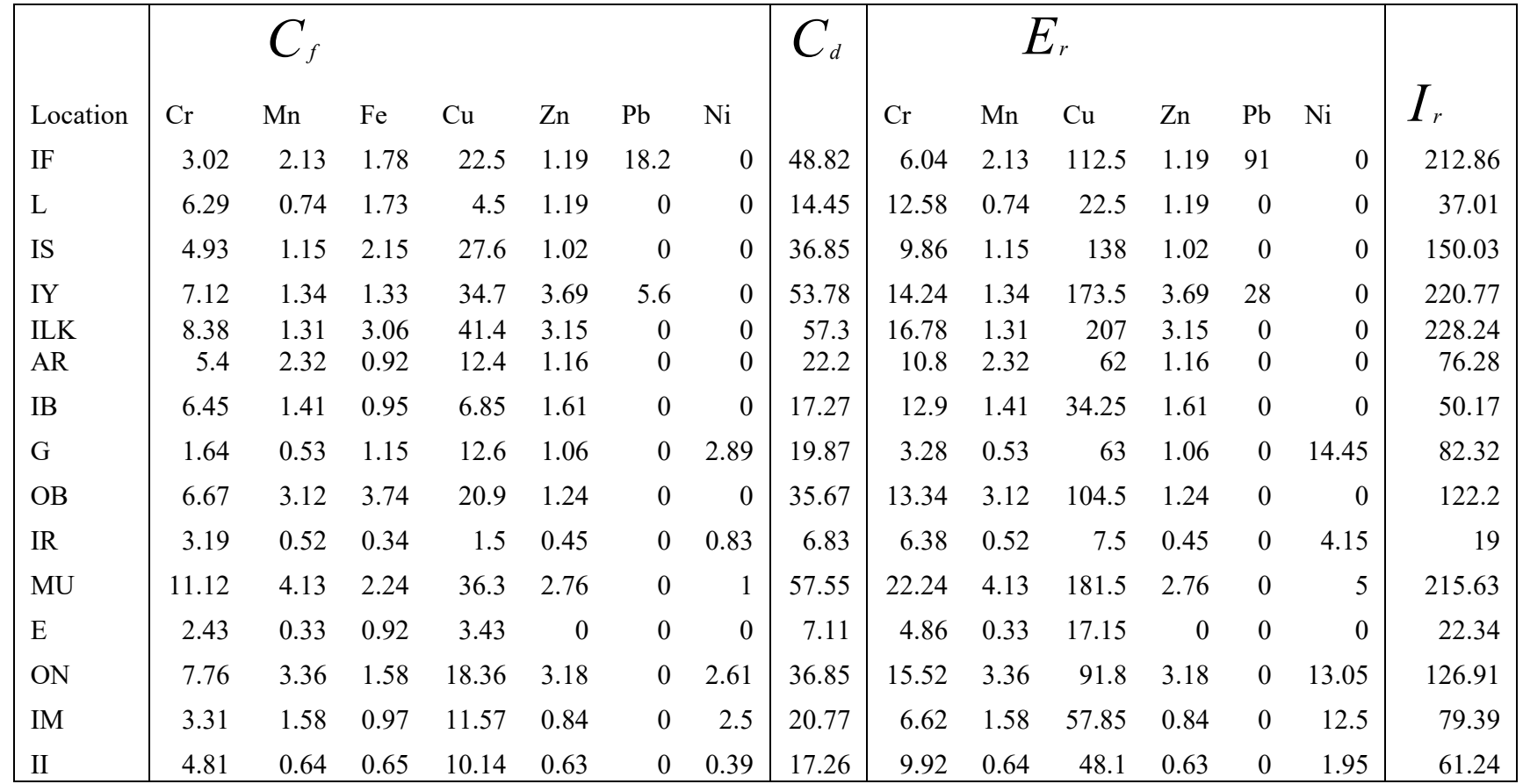




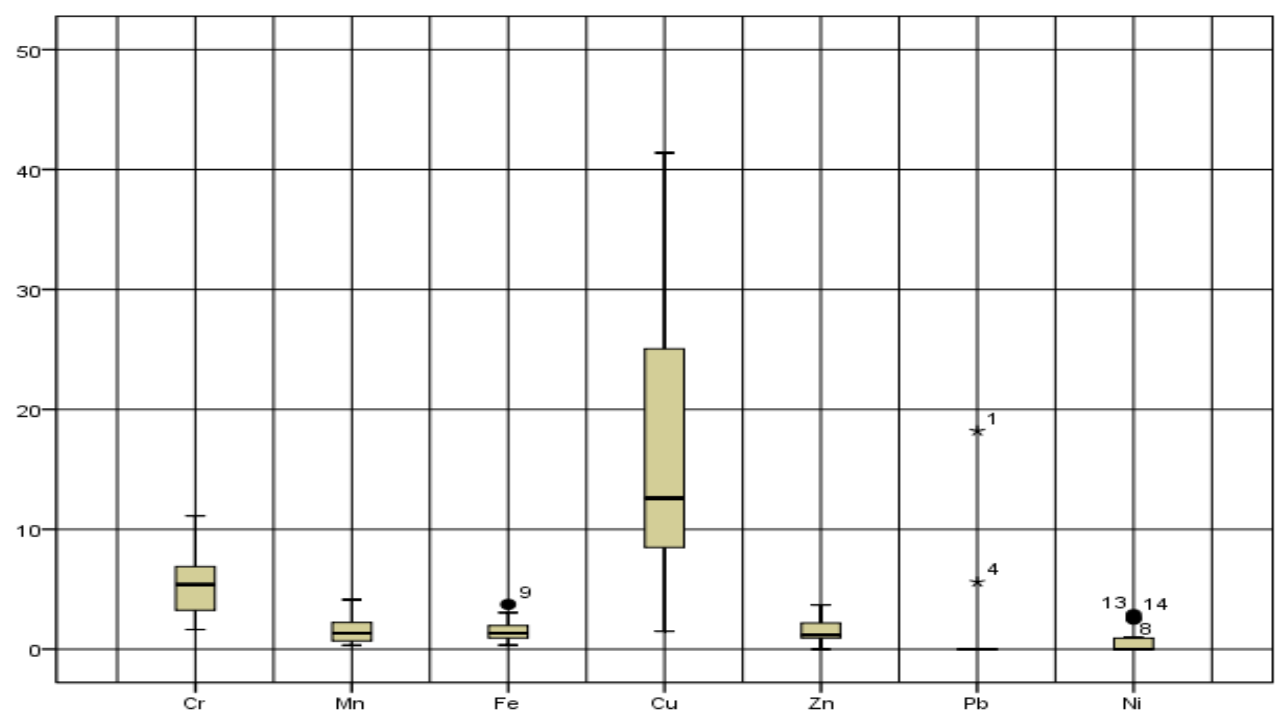

Figure 4a. Box plots of $C_{f}$ for studied heavy metals in Ife/Ijesa goldmine tailings.

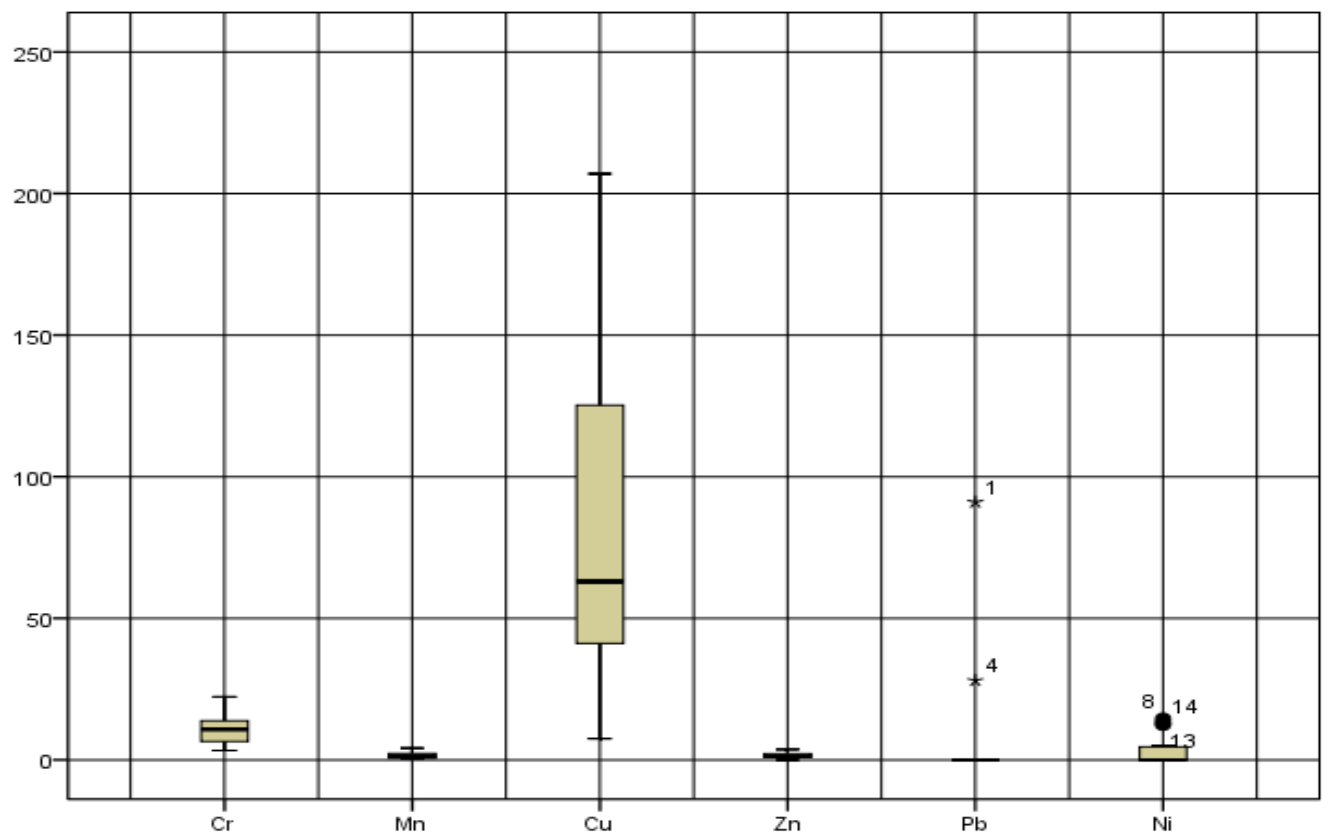

Figure 4b. Box plots of $E_{r}$ for studied heavy metals in Ife/ljesa goldmine tailings.

\section{Conclusion}

Multivariate analysis is a reliable tool for characterizing and prediction of tailings behavior. PCA shows that natural and geochemical source are possible means of contamination in the tailings. The analysis of $I_{\text {geo }}$ of all the element examined indicated moderately-heavily to heavily extremely contaminated while the $E_{r}$ of all elements showed a low level of heavy metals except $\mathrm{Cu}$ which shows considerable contamination and should of concern to the environmental policy maker.

\section{Conflict of Interest}

The authors declare that there is no conflict of interest in this manuscript. 


\section{References}

[1] Y.A. Ekwue et al., Assessment of metal contamination in soil and plants from abandoned secondary, and primary goldmines in Osun State, Nigeria, Journal of Soil Science and Environmental Management. 3(11) (2012) 262-274.

[2] D.H. Zeng, F.S. Chen. Heavy metal concentrations in redeveloping soil of mine spoil under plantations of certain native woody species in dry tropical environment, India, J Environ. Sci. (2005) 168-174.

[3] M.C. Navarro et al., Abandoned mine sites as a source of contamination by heavy metals: A case study in a semi-arid zone, J. Geochem. Explor. 96 (2008) 183-193.

[4] A.N. Singh, D.H. Zeng, F.S. Chen, Heavy metal concentrations in redeveloping soil of mine spoil under plantations of certain native woody species in dry tropical environment, India, J Environ. Sci. 1 (2005) 168-174.

[5] J. Loredo et al., Influence of industry on the geochemical urban environment of Mieres (Spain) and associated health risk. Environ. Geochem. Health. 25(3) (2003) 307-323.

[6] W.A. Manasreh, Assessment of trace metals in street dust of Mutah city, Karak, Jordan. Carpath, J. Earth Environ. Sci. 5 (2010) 5-12.

[7] M. Saeedi, L.Y. Li, M. Salmanzadeh, Heavy metals and polycyclic aromatic hydrocarbons: Pollution and ecological risk assessment in street dust of Tehran, J. Hazard. Matter. 227-228 (2012) 9-17.

[8] X. Wang et al., Source identification, size distribution and indicator screening of airborne trace metals in Kanazawa, Japan. J. Aerosol Sci. 36(2) (2004) 197-210.

[9] K. Park, H.D. Dam, Characterization of metal aerosols in PM10 from urban, industriSingh Asian dust sources. Environ. Monit. Assess. 160(1-4) (2010) 289-300.

[10] P.W. Abrahams, Soils: Their implications to human health. The Science of the Total Environment. 29 (2002) 11-32.

[11] Ş. Tokalığlu, Ş. Kartal, Multivariate analysis of the data and speciation of heavy metals in street dust samples from the organized industrial district in Kayseri (Turkey). Atmos. Environ. 40(16) (2006) 2797-2805.

[12] C. Mendiguchi'a et al., Using chemometric tools to assess anthropogenic effects in river water. A case study: Guadalquivir River (Spain). Analytica Chimica Acta.515(2004)143-149.

[13] H. Yongming et al., Multivariate analysis of heavy metal contamination in urban dusts of Xi'an, Central China. Sci. Total Environ. 355(1) (2006) 176-186.

[14] H.F. Kaiser, The application of electronic computers to factor analysis. Educ. Psychol. Meas. 20 (1960) 141-151.

[15] S. Fri'as et al., Classification of commercial wines from the Canary Islands (Spain) by chemometric techniques using metallic contents, Talanta. 59 (2003) 335-344.

[16] G. Muller, Index of geoaccumulation in sediments of the Rhine River, Geojournal. 2(3) (1996) 108-118.

[17] L. Hakanson, An ecological risk index for aquatic pollution control. A sedimentological approach, Water Resources. 28 (1980) 975-1001.

[18] R. Tang et al., The spatial characteristics and pollution levels of metals in urban street dust of Beijing, China. Appl. Geochem. 35 (2013) 88-98. 